\title{
Caracterização física e química de híbridos de tomate em diferentes estádios de maturação produzidos em Baraúna, Rio Grande do Norte
}

\author{
Rafaella Martins de Araújo Ferreira ${ }^{*}$, Welder de Araújo Rangel Lopes², Edna Maria Mendes Aroucha ${ }^{3}$ \\ Neidiane Conceição Sales Mano ${ }^{4}$, Cleiniane Maria Guerra de Sousa ${ }^{1}$
}

\begin{abstract}
RESUMO
O tomate é uma das olerícolas mais consumidas no mundo. Na região nordeste do Brasil, é comum a comercialização de cultivares industriais para consumo in natura. Este trabalho teve como objetivo avaliar algumas características de qualidade de dois híbridos de tomate industrial ('Mariana' e 'SM -16'), em quatro estádios de maturação (verde - 1; salada - 2; colorido - 3; vermelho -4). Após a colheita, os frutos foram transportados para o Laboratório de Tecnologia de Alimentos da Universidade Federal Rural do Semi-Árido, onde foram selecionados de acordo com a uniformidade de maturação e avaliados de acordo com diâmetro longitudinal e transversal, massa de matéria fresca, firmeza da polpa, sólidos solúveis, $\mathrm{pH}$, vitamina $\mathrm{C}$ e açúcares totais. $\mathrm{O}$ delineamento experimental foi o inteiramente casualizado, em esquema fatorial $2 \times 4$ (dois cultivares e quatro estádios de maturação). Os dados foram submetidos à análise de variância e as médias comparadas pelo teste de Tukey, a 5\%. Observaram-se diferenças na qualidade física e química dos frutos, entre híbridos e entre estádios de maturação. A massa de matéria fresca dos frutos, o diâmetro transversal e a firmeza da polpa dos tomates pertencentes ao híbrido 'SM-16' foram superiores aos do híbrido 'Mariana'. Houve aumento da massa de matéria fresca até o estádio de maturação 3 e decréscimo da firmeza e do pH da polpa, com o amadurecimento dos frutos. O teor de vitamina $\mathrm{C}$ dos frutos aumentou do estádio 1 para o 2, e o híbrido 'Mariana' apresentou maior teor de vitamina $\mathrm{C}$.
\end{abstract}

Palavras-chave: Lycopersicon esculentum Mill., estádios de maturação, vitamina C, açúcares totais.

\section{ABSTRACT \\ Physical and chemical characterization of hybrid tomato at different stages of maturation in Baraúna-Rio Grande do Norte State, Brasil}

The tomato is one of the most consumed vegetables in the world. In the northeast region of Brazil, it is common the trade of industrial cultivars for fresh consumption. This study aimed to evaluate some quality characteristics of two hybrids of tomato ('Mariana' and 'SM -16') at four maturity stages (green - 1, salad - 2, colored - 3 and red - 4). After harvest, fruits were transported to the Laboratory of Food Technology of the Federal Rural University of Semi-arid, where they were selected for uniformity of maturity and evaluated for longitudinal and transverse diameter, fresh weight, firmness, soluble solids, $\mathrm{pH}$, vitamin $\mathrm{C}$ and total sugars. The experimental design was completely randomized, in a 2 x 4 factorial (two cultivars and four maturity stages). Data were subjected to analysis of variance and means compared by the Tukey test at 5\%. In the fresh fruit of hybrid 'SM-16', transverse diameter and firmness were higher

Recebido para publicação em 21/03/2011 e aceito em 11/06/2012.

'Engenheiras-Agrônomas. Mestrandas do Departamento de Fitotecnia, Universidade Federal Rural do Semi-Árido, Rodovia BR 110, Km 47, Costa e Silva, 59625-900, Mossoró, Rio Grande do Norte, Brasil. rafaellamarafe@gmail.com; cleiniane guerra@hotmail.com (*Autora correspondente)

${ }^{2}$ Engenheiro-Agrônomo, Mestre. Doutorando do Departamento de Fitotecnia, Universidade Federal Rural do Semi-Árido, Rodovia BR 110, Km 47, Costa e Silva, 59625-900, Mossoró, Rio Grande do Norte, Brasil. welder.lopes@hotmail.com

${ }^{3}$ Engenheira-Agrônoma, Doutora. Departamento de Agrotecnologia e Ciências Sociais, Universidade Federal Rural do Semi-Árido, Rodovia BR 110, Km Costa e Silva, 59625-900, Mossoró, Rio Grande do Norte, Brasil. aroucha@ufersa.edu.br

${ }^{4}$ Engenheira-Agrônoma. Universidade Federal Rural do Semi-Árido, Rodovia BR 110, Km 47, Costa e Silva, 59625-900, Mossoró, Rio Grande do Norte, Brasil. neidianesmano@hotmail.com

Rev. Ceres, Viçosa, v. 59, n.4, p. 506-511, jul/ago, 2012 
than in the hybrid 'Mariana'. There was an increase of fresh weight at the maturation stage 3, and a decrease in firmness and $\mathrm{pH}$ of the pulp and fruit ripening. The vitamin $\mathrm{C}$ content of fruits increased from stage 1 to 2 , and the hybrid 'Mariana' showed the highest content of vitamin $\mathrm{C}$.

Key words: Lycopersicon esculentum Mill., maturity stages, vitamin C, total sugars.

\section{INTRODUÇÃO}

A cultura do tomateiro apresenta grande relevância no Brasil, tanto por sua representatividade em área plantada, quanto pela quantidade produzida, sendo o mais importante cultivo olerícola, com mais de 3,7 milhões de toneladas produzidas no ano de 2010 (IBGE, 2010). Além disso, é uma das hortaliças mais consumidas no mundo, tanto in natura, como processada, nas formas de suco, molho, pasta, desidratada e doce dentre outros (FAO, 2010).

O nordeste brasileiro apresenta ótimas condições para o cultivo do tomate, sendo responsável por 16,60\% da produção nacional, com destaque para os Estados da Bahia, Pernambuco e Ceará, responsáveis, em 2010, por 49,11; 25,41 e 18,58\%, respectivamente, da produção regional. O Rio Grande do Norte, apesar das condições climáticas favoráveis, ainda não alcançou produção suficiente para evitar a importação de outros estados, sendo responsável por apenas $1,09 \%$ da produção regional (IBGE, 2010).

O ponto de colheita do tomate depende, de maneira geral, da distância entre o local de produção até o mercado atacadista e, ou, varejista, e do tempo que o fruto demanda desde o comerciante até chegar ao consumidor. Todavia, estudos têm demonstrado que o tomate colhido maduro tem sabor e aroma superiores aos do tomate colhido em estádios de amadurecimento anteriores (Alvarenga, 2000). Deve-se considerar também a exigência do mercado consumidor. Em alguns mercados, como Goiânia, comercializam-se os frutos colhidos ao se iniciar o desenvolvimento da coloração rosada, um estádio considerado "verde" em outros mercados, sendo os frutos de coloração vermelha desvalorizados (Filgueira, 2007).

A classificação do tomate para consumo in natura, pela legislação brasileira vigente, estabelece os subgrupos do tomate em função de sua coloração, o que está relacionado com o estádio de maturação. Para isto, o tomate é classificado em cinco subgrupos: verde maduro, pintado, rosado, vermelho e vermelho maduro.

Os subgrupos são diferenciados da seguinte maneira: verde maduro agrega os frutos que estão iniciando o amarelecimento na região apical do fruto; pintado (de vez) refere-se aos frutos com as cores amarelo, rosa ou verme- lho entre 10 e $30 \%$ da superfície da casca; rosado comporta os frutos com 30 a $60 \%$ da casca vermelha; vermelho é a classificação dos frutos que apresentam entre 60 e $90 \%$ da sua superfície vermelha; e vermelho maduro é o subgrupo que refere-se aos frutos com mais de $90 \%$ da superfície vermelha (Brasil, 1995).

Entretanto, na prática, os produtores e embaladores utilizam a nomenclatura proposta pela Ceasaminas que identifica os referidos subgrupos como verde, salada, colorido, vermelho e molho, respectivamente (Ceasaminas, 2001).

A qualidade do tomate está relacionada com o estádio de maturação do fruto, pois é ele que define o momento da colheita. Durante a maturação do tomate, produzem-se mudanças fisiológicas e bioquímicas que induzem a mudanças de cor, sabor, textura e aroma, definindo o momento da colheita. O estádio verde maduro (início de mudança de cor) é considerado o primeiro indicador visual para o índice de maturação. De um modo geral, a cor é o atributo de qualidade mais atrativo para o consumidor (Chitarra \& Chitarra, 2005).

As mudanças que ocorrem na composição do tomate durante a maturação têm sido estudadas por meio de algumas características de qualidade, tais como: tamanho do fruto, acidez, sólidos solúveis, teor de açúcares, textura, dentre outros (Resende et al., 2004; Moura et al., 2005; Ferreira et al., 2010).

Tendo em vista a variabilidade genética dos híbridos de tomate comercial e as constantes mudanças que os frutos sofrem ao longo do seu desenvolvimento, foi objetivo avaliar algumas características de qualidade pós-colheita dos híbridos de tomate 'Mariana' e 'SM -16', em quatro estádios de maturação, produzidos no município de Baraúna, Rio Grande do Norte.

\section{MATERIAL E MÉTODOS}

O plantio do tomateiro (híbridos 'Mariana' e 'SM-16') foi realizado na empresa WG Fruticultura, sítio Sumidouro, localizada no município de Baraúna, em Cambissolo Háplico de textura argilosa (Embrapa, 1999). A área está situada à latitude sul de $5^{\circ} 05^{\prime}$ e longitude oeste de $37^{\circ} 38^{\prime}$, em altitude de $95 \mathrm{~m}$. O clima da região, de acordo com a classificação de Köppen, é do tipo BSwh', ou seja, quen- 
te e seco; com duas estações climáticas: uma seca que vai, geralmente, de junho a janeiro e uma chuvosa, de fevereiro a maio (Carmo Filho et al., 1991).

Para a obtenção das mudas, procedeu-se a semeadura em bandejas de poliestireno expandido, contendo substrato comercial Golden Mix ®. Após 25 dias, as mudas foram transplantadas. O espaçamento utilizado foi de 2,0 m entre fileiras e 0,50 m entre plantas, com áreas total e útil de 84 e $24 \mathrm{~m}^{2}$. O preparo do solo constou de uma aração e gradagem, seguido do sulcamento em linhas, com profundidade de $20 \mathrm{~cm}$, onde foi realizada a adubação de plantio com $400 \mathrm{~kg} \mathrm{ha}^{-1}$ de fosfato monoamônico (MAP), com posterior fechamento dos sulcos.

O sistema de irrigação utilizado foi o gotejamento, com a quantidade de água variando conforme a evapotranspiração (ETc) da cultura. Utilizou-se cobertura do solo com polipropileno preto nas fileiras de plantas. Foram efetuadas adubações em cobertura diariamente, via fertirrigação, seguindo-se as recomendações da análise de solo e obedecendo-se aos estádios de desenvolvimento da cultura. Para tanto, utilizaram-se $225 \mathrm{~kg} \mathrm{ha}^{-1} \mathrm{de}$ $\mathrm{N}_{2}, 125 \mathrm{~kg} \mathrm{ha}^{-1}$ de $\mathrm{P}_{2} \mathrm{O}_{5}$ e $390 \mathrm{~kg} \mathrm{ha}^{-1}$ de $\mathrm{K}_{2} \mathrm{O}$.

Os frutos foram colhidos em outubro de 2009, em quatro estádios de maturação, conforme critério presente no Manual de Classificação de Tomate (Ceasaminas, 2001), sendo cada estádio enumerado da seguinte forma: estádio 1 (verde); estádio 2 (salada); estádio 3 (colorido) e estádio 4 (vermelho). Em seguida, foram transportados em caixas de plástico para o Laboratório de Tecnologia de Alimentos, do Departamento de Agrotecnologia e Ciências Sociais da Universidade Federal Rural do Semi-Árido (UFERSA), onde se procedeu à seleção quanto à uniformidade de maturação.

O delineamento experimental utilizado foi o inteiramente casualizado em esquema fatorial $2 \times 4$. O primeiro fator foi representado pelos híbridos ('Mariana' e 'SM-16') e o segundo pelos estádios de maturação, com quatro repetições de quatro frutos.

Foram avaliadas as seguintes características de qualidade: diâmetro longitudinal e transversal dos frutos medidos com o auxílio de paquímetro manual, os resultados expressos em centímetros; massa de matéria fresca dos frutos - determinada por pesagem em balança digital, com resultados expressos em gramas; firmeza da polpa - medida por meio de um penetrômetro digital MCCORMICK, sendo os valores expressos em Newton; teor de sólidos solúveis (SS) - determinados com o auxílio de refratômetro digital ATAGO PR-1000 e os resultados expressos em percentagem; $\mathrm{pH}$ - determinado com o auxílio de um potenciômetro digital modelo DMPH-2 Digimed, previamente calibrado em soluções tampão de pH 4,0 e 7,0; vitamina C-determinada por titulometria de neutralização com solução de DFI (2,6 diclorofenol- indofenol 0,02\%), sendo os resultados expressos em $\mathrm{mg}$ de vitamina $\mathrm{C} / 100 \mathrm{~g}$ de polpa; açúcares solúveis totais (AST) - determinados pelo método da antrona e seus resultados expressos em percentagem.

Os dados foram submetidos às análises de variância, por meio do software SISVAR (Ferreira, 2003), sendo as médias comparadas pelo teste de Tukey a 5\% de probabilidade.

\section{RESULTADOS E DISCUSSÃO}

Houve efeito significativo da interação híbridos x estádios de maturação para as características diâmetro transversal, firmeza da polpa e açúcares solúveis totais. Verificou-se efeito isolado para híbridos e estádios de maturação para as características massa de matéria fresca, $\mathrm{pH}$ e vitamina C (Tabelas 1 e 2).

Avaliando-se os estádios de maturação, não se observou diferença no diâmetro transversal dos frutos, entre os estádios de maturação para o híbrido 'Mariana'. Entretanto, para o híbrido 'SM-16' houve incremento no diâmetro transversal, entre os estádios 2 e 3 de maturação, atingindo-se o limite máximo de $5,90 \mathrm{~cm}$ (Tabela 1). Vilas Boas et al. (1999) estudando híbridos de primeira geração de tomate multilocular em quatro estádios de maturação, detectaram valor médio para o diâmetro transversal dos frutos de 7,37 cm.

Desdobrando híbridos de tomate dentro de cada estádio de maturação, pôde-se observar que o híbrido 'SM16' sobressaiu-se, quanto ao diâmetro transversal dos frutos, em todos os estádios de maturação, com média de $5,66 \mathrm{~cm}$, enquanto o híbrido 'Mariana' apresentou valor médio de 5,02 cm (Tabela 1). De acordo o programa brasileiro para a modernização da horticultura, esses frutos são classificados como médios (Ceasaminas, 2001).

Verificou-se, com o desdobramento dos estádios de maturação dentro dos híbridos de tomate, que a firmeza da polpa dos frutos pertencentes ao híbrido 'Mariana' não apresentou diferença estatística ao longo da maturação, enquanto, para o híbrido 'SM-16', os tomates pertencentes aos estádios 1 e 2 de maturação apresentaram firmeza de polpa maior, quando comparado com a dos frutos dos estádios 3 e 4 de maturação (Tabela 1). O amaciamento de polpa é resultante da solubilização da parede celular (Kluge \& Minami, 1997). Dessa forma, à medida que o fruto vai amadurecendo, há transformação das pectinas insolúveis (protopectina) em pectina solúvel, resultando no amaciamento da polpa (Cheftel \& Cheftel, 1988; Braverman \& Berk, 1998).

Avaliando-se os híbridos de tomate dentro de cada estádio de maturação, observa-se que a firmeza da polpa do híbrido 'SM-16' foi superior à dos frutos do híbrido 'Mariana', exceto no estádio 4, no qual os dois híbridos 
apresentaram valores estatisticamente iguais para essa característica (Tabela 1). Essa variação na firmeza de polpa em frutos de tomate com diferentes genótipos foi verificada também por Rosa et al. (2011). Estes autores detectaram firmeza de $10,64 \mathrm{~N}, 5,09 \mathrm{~N}, 4,82 \mathrm{~N}$ e 7,65 N nos acessos San Marzano, Chico Grande, Amish Paste e EUA 05 , respectivamente.

A firmeza da polpa é um dos atributos de qualidade mais importante para a comercialização do tomate, tendo em vista que este parâmetro é bastante exigido pelos consumidores, o que influencia de forma significativa a opção de compra (Andreuccetti et al., 2005). A firmeza é importante também na vida útil dos frutos, pois confere resistência a danos durante a colheita, transporte e fase de comercialização (Embrapa, 2006).

Com relação à concentração de açúcares solúveis totais, pode-se verificar que, no estádio 3 de maturação, o híbrido 'Mariana' apresentou maior concentração que o híbrido 'SM-16', enquanto, nos demais estádios de maturação, os dois híbridos apresentaram concentração de AST estatisticamente iguais (Tabela 1). Porém, ao longo da maturação, pode-se observar que a concentração de AST não variou significativamente no híbrido 'Mariana', enquanto no híbrido 'SM-16' apresentou decréscimo no estádio 3 de maturação. Moura et al. (2005) também detectaram decréscimo na concentração de açú- cares solúveis totais, até o estádio 3 de desenvolvimento (11 a $40 \%$ do fruto vermelho), em tomates 'Santa Maria'.

Pode-se observar que o $\mathrm{pH}$ decresceu, até o estádio 3 de maturação dos dois híbridos de tomate estudados (Tabela 2). Entretanto, houve um pequeno acréscimo no $\mathrm{pH}$ no estádio final da maturação. Valores semelhantes de $\mathrm{pH}$ $(4,40$ e 4,60) foram detectados, em tomate 'Santa Clara', por Tavares \& Rodriguez-Amaya (1994). Chitarra \& Chitarra (2005) explicaram que as mudanças na concentração dos ácidos orgânicos durante o desenvolvimento de frutos diferem conforme a espécie, podendo aumentar ou diminuir com a maturação.

A massa de matéria fresca média dos frutos do híbrido 'SM-16' (115,79 g) foi superior à do híbrido 'Mariana' $(107,86$ g) (Tabela 2). No entanto, os valores para a massa de matéria fresca média, detectados neste experimento, foram inferiores aos especificados, pelas empresas detentoras dos híbridos 'SM-16' (Seminis) e 'Mariana' (Sakata), com massa média de 200 e 125 gramas, respectivamente.

Houve diferenças significativas quanto à massa de matéria fresca dos frutos entre estádios de maturação. Os frutos, no estádio de maturação 1 , apresentaram massa significativamente menor, quando comparada com a massa dos frutos nos estádios 3 e 4, que se apresentaram mais pesados (Tabela 2 ). Pode-se notar que a taxa de cres-

Tabela 1. Valores médios das características diâmetro transversal (DT), firmeza da polpa e açúcares solúveis totais (AST), avaliadas nos híbridos 'Mariana' e 'SM-16', em função dos estádios de maturação dos frutos

\begin{tabular}{|c|c|c|c|c|c|c|}
\hline \multirow{2}{*}{$\begin{array}{l}\text { Estádios de } \\
\text { maturação }\end{array}$} & \multicolumn{2}{|c|}{ DT (cm) } & \multicolumn{2}{|c|}{ Firmeza $(\mathbf{N})$} & \multicolumn{2}{|c|}{$\operatorname{AST}(\%)$} \\
\hline & 'Mariana' & 'SM-16' & 'Mariana' & 'SM-16' & 'Mariana' & 'SM-16' \\
\hline Estádio 1 & $5,10 \mathrm{aB}$ & $5,60 \mathrm{abA}$ & $13,23 \mathrm{aB}$ & $18,93 \mathrm{aA}$ & $2,75 \mathrm{aA}$ & $2,25 \mathrm{aA}$ \\
\hline Estádio 2 & $5,05 \mathrm{aB}$ & $5,50 \mathrm{bA}$ & $13,31 \mathrm{aB}$ & $17,10 \mathrm{aA}$ & $2,50 \mathrm{aA}$ & $2,25 \mathrm{aA}$ \\
\hline Estádio 3 & $4,87 \mathrm{aB}$ & $5,90 \mathrm{aA}$ & $13,08 \mathrm{aB}$ & $14,88 \mathrm{bA}$ & $2,75 \mathrm{aA}$ & $1,00 \mathrm{bB}$ \\
\hline Estádio 4 & $5,07 \mathrm{aB}$ & $5,65 \mathrm{abA}$ & $12,88 \mathrm{aA}$ & $12,92 \mathrm{bA}$ & $2,50 \mathrm{aA}$ & $2,00 \mathrm{abA}$ \\
\hline$\overline{\mathrm{CV}(\%)}$ & \multicolumn{2}{|c|}{3,53} & \multicolumn{2}{|c|}{7,75} & \multicolumn{2}{|c|}{24,00} \\
\hline
\end{tabular}

* Médias seguidas de mesma letra minúscula, na coluna, e maiúscula, na linha, não diferem entre pelo teste de Tukey a 5\% de probabilidade.

Tabela 2. Valores médios das características massa fresca (MF), diâmetro longitudinal (DL), pH, teor de sólidos solúveis (SS) e vitamina C avaliadas nos frutos dos híbridos de tomate 'Mariana' e 'SM-16', em função dos estádios de maturação dos frutos

\begin{tabular}{lccccc}
\hline \multirow{2}{*}{ Híbridos } & \multicolumn{5}{c}{ Características avaliadas } \\
\cline { 2 - 6 } & MF $(\mathbf{g})$ & DL $(\mathbf{c m})$ & $\mathbf{p H}$ & $\mathbf{S S}(\mathbf{\%})$ & Vit. C $(\mathbf{m g} / \mathbf{1 0 0 g})$ \\
\hline 'Mariana' & $107,86 \mathrm{~b}$ & $7,89 \mathrm{a}$ & $4,35 \mathrm{a}$ & $3,87 \mathrm{a}$ & $15,38 \mathrm{a}$ \\
'SM-16' & $115,79 \mathrm{a}$ & $7,84 \mathrm{a}$ & $4,35 \mathrm{a}$ & $3,75 \mathrm{a}$ & $13,43 \mathrm{~b}$ \\
\hline Estádios de maturação & & & & \\
\hline Estádio 1 & $101,65 \mathrm{~b}$ & $7,65 \mathrm{a}$ & $4,56 \mathrm{a}$ & $3,68 \mathrm{a}$ & $10,25 \mathrm{~b}$ \\
Estádio 2 & $110,16 \mathrm{ab}$ & $7,82 \mathrm{a}$ & $4,26 \mathrm{c}$ & $3,97 \mathrm{a}$ & $16,66 \mathrm{a}$ \\
Estádio 3 & $116,92 \mathrm{a}$ & $8,01 \mathrm{a}$ & $4,24 \mathrm{c}$ & $3,82 \mathrm{a}$ & $15,95 \mathrm{a}$ \\
Estádio 4 & $118,56 \mathrm{a}$ & $7,98 \mathrm{a}$ & $4,34 \mathrm{~b}$ & $3,76 \mathrm{a}$ & $14,78 \mathrm{a}$ \\
\hline CV(\%) & 9,24 & 3,63 & 0,99 & 9,63 & 15,68 \\
\hline
\end{tabular}

*Médias seguidas de mesma letra minúscula, na coluna, não diferem entre si pelo teste de Tukey a 5\% de probabilidade. 
cimento máximo ocorreu até o estádio de maturação 2, quando não se observaram mudanças significativas de massa de matéria fresca dos frutos. Esse estádio marcou a transição entre o crescimento e maturidade do fruto, evidenciada pela coloração dos frutos nesse estádio.

Segundo Kays (1997), durante o desenvolvimento ocorre nos frutos uma série de transformações que podem ser físicas, químicas, bioquímicas ou fisiológicas. E antes mesmo de cessar o crescimento máximo, alguns atributos de qualidade podem ser detectados nos frutos, entre estes a presença de pigmentos.

Para o conteúdo de vitamina $\mathrm{C}$, houve diferenças entre os híbridos de tomates. O híbrido 'Mariana' apresentou valores superiores $(15,38 \mathrm{mg} / 100 \mathrm{~g})$ aos do híbrido 'SM-16' (13,43 mg/100g) (Tabela 2). Esses resultados permaneceram dentro da faixa de vitamina $\mathrm{C}$ detectada em tomate por Carvalho et al. (2003), variando de 11,2 a 21,6 mg/100g de frutos. Contudo, os teores de vitamina $\mathrm{C}$ encontrados neste trabalho foram inferiores ao considerado como ideal (mínimo de $23 \mathrm{mg} / 100 \mathrm{~g}$ ) por Crawford (1985).

Verificaram-se diferenças também nos teores de vitamina $\mathrm{C}$, conforme os estádios de maturação (Tabela 2). Houve acréscimo no conteúdo de vitamina $\mathrm{C}$ nos tomates do estádio de maturação $1(10,25 \mathrm{mg} / 100 \mathrm{~g})$ para o estádio $2(16,66 \mathrm{mg} / 100 \mathrm{~g})$. Andreuccetti et al. (2007) detectaram comportamento semelhante em tomate híbrido 'Andréa'. Os autores observaram que há incremento no teor de vitamina C no início da maturação e, logo em seguida, ocorre decréscimo dessa vitamina.

O diâmetro longitudinal não apresentou diferença significativa para estádio de maturação ou híbrido (Tabela 2). Os frutos pertencentes aos híbridos estudados, por apresentarem diâmetro longitudinal superior ao diâmetro transversal, são classificados como oblongos (Brasil, 2002). Da mesma maneira, para o teor de sólidos solúveis, não foi detectado efeito isolado para os fatores híbrido e estádios de maturação (Tabela 2). Brackmann et al. (2007) também detectaram que o estádio de maturação não influenciou no teor de sólidos solúveis de tomate 'Cronus'. Estes autores explicaram que tomates colhidos parcialmente ou totalmente maduros apresentam, após o período de armazenamento, uma qualidade semelhante em termos de sabor.

\section{CONCLUSÕES}

Há diferenças nas características físicas e químicas de qualidade dos frutos entre híbridos 'Mariana' e 'SM-16', conforme o estádio de maturação.

A massa de matéria fresca dos frutos, o diâmetro transversal e a firmeza da polpa dos tomates pertencentes ao híbrido 'SM-16' são superiores aos do híbrido 'Mariana' .
Há aumento da massa de matéria fresca, até o estádio de maturação 3, e decréscimo da firmeza e do pH da polpa, com o amadurecimento dos frutos.

O teor de vitamina $\mathrm{C}$ dos frutos aumenta, do estádio 1 para o 2, e o híbrido 'Mariana' apresenta maior teor de vitamina $\mathrm{C}$.

O híbrido 'SM-16' pode ser indicado para o plantio, por proporcionar um fruto com maior peso e possuir, ainda, maior resistência, sendo menos susceptível aos danos da colheita e do transporte; seus frutos devem ser colhidos no estádio 2 de maturação, para comercialização à longa distância, e no estádio 3, para rápida comercialização, com transporte a curtas distâncias.

\section{REFERÊNCIAS}

Alvarenga MAR (2000) Tomate: produção em campo, em casa de vegetação e em hidroponia. Lavras, Editora UFLA. 400p.

Andreuccetti C, Ferreira MD \& Tavares M (2005) Perfil dos compradores de tomate de mesa em supermercados da região de Campinas. Horticultura Brasileira, 23:148-153.

Andreuccetti C, Ferreira MD, Moretti CL \& Honório SL (2007) Qualidade pós-colheita de frutos de tomate cv. Andréa tratados com etileno. Horticultura Brasileira, 25:122-126.

Brackmann A, Steffens CA, Andriolo JL \& Pinto JAV (2007) Armazenamento de tomates cultivar "Cronus" em função do estádio de maturação e da temperatura. Ciência Rural, 37:12951300 .

Brasil (1995) Ministério da Agricultura do Abastecimento e da Reforma Agrária. Portaria no 553 de 30 de agosto de 1995. Dispõe sobre a Norma de Identidade, Qualidade, Acondicionamento e Embalagem do Tomate in natura, para fins de comercialização e Revoga as especificações de Identidade, Qualidade, Acondicionamento e Embalagem do Tomate, estabelecidas pela Portaria $\mathrm{n}^{\circ}$ 76, de 25 de fevereiro de 1975. Diário Oficial da República Federativa do Brasil, Brasília, set. 1995.

Brasil (2002) Ministério da Agricultura, Pecuária e Abastecimento. Portaria SARC no 085 de 06 de março de 2002. Propõe o Regulamento técnico de identidade e qualidade para classificação do tomate. Diário Oficial da República Federativa do Brasil, Brasília, mar. 2002. (Consulta pública).

Braverman JBS \& Berk Z (1998) Introducción a la bioquímica de los alimentos. Ciudad de México, Editorial El Manual Moderno. $358 \mathrm{p}$.

Carmo Filho F, Espínola Sobrinho J \& Maia Neto JM (1991) Dados climatológicos de Mossoró: um município semi-árido nordestino. Mossoró, ESAM. 121p. (Coleção mossoroense, 30).

Carvalho JOM, Luz JMQ, Juliantti FC, Melo LC, Teodoro REF \& Lima LML (2003) Desempenho de famílias e híbridos comerciais de tomateiro para processamento industrial com irrigação por gotejamento. Horticultura Brasileira, 21:525-533.

Ceasaminas (2001) Programa brasileiro para modernização da horticultura. Agroqualidade: Tomate. Disponível em: < http:// www.ceasaminas.com.br/ agroqualidade/tomate.asp >. Acessado em: 25 de maio de 2012.

Cheftel JC \& Cheftel H (1988) Introduccion a la bioquímica y tecnología de los alimentos. Zaragoza, Acribia. 333p.

Chitarra MIF \& Chitarra AB (2005) Pós-colheita de frutos e hortaliças: fisiologia e manuseio. $2^{\text {a }}$ ed. Lavras, UFLA. 783p. 
Crawford AMC (1985) Alimentos: Seleção e preparo. Rio de Janeiro, Record. 160p.

Embrapa (1999) Sistema brasileiro de classificação de solos. Brasília, Serviço de produção de informação. 412p.

Embrapa (2006) Sistema de produção: Cultivo de tomate para industrialização. Disponível em: <http:// sistemaproducao.cnptia.embrapa.br/FontesHTML/ Tomate/ TomateIndustrial/.htm2006>. Acessado em: 22 de março de 2012.

FAO (2010) Disponível em: <http://faostat.fao.org >. Acessado em: 20 de janeiro de 2012

Ferreira DF (2003) SISVAR: Sistema de análises estatísticas. Lavras, DEX/UFLA.

Ferreira SMR, Quadros DA, Karkle ENL, Lima JJ, Tullio LT \& Freitas RJS (2010) Qualidade pós-colheita do tomate de mesa convencional e orgânico. Ciência e Tecnologia de Alimentos, 30:858-864.

Filgueira FAR (2007) Novo manual de olericultura: Agrotecnologia moderna na produção e comercialização de hortaliças. $3^{\mathrm{a}}$ ed. Viçosa, UFV. 421p.

IBGE (2010) Levantamento sistemático da produção agrícola. Rio de Janeiro, 23:1-80.

Kays SJ (1997) Postharvest physiology of perishable plant products. Athens, Exon Press. 532p.
Kluge RA \& Minami K (1997) Efeito de ésteres de sacarose no armazenamento de tomates 'Santa Clara'. Scientia Agrícola, $54: 39-44$.

Moura ML, Finger FL, Mizobutsi GP \& Galvão HL (2005) Fisiologia do amadurecimento na planta do tomate 'Santa Clara' e do mutante 'Firme'. Horticultura Brasileira, 23:81-85.

Resende JM, Chitarra MIF, Maluf WR, Chitarra AB \& Saggin Júnior OJ (2004) Atividade de enzimas pectinametilesterase e poligalacturonase durante o amadurecimento de tomates do grupo multilocular. Horticultura Brasileira, 22:206-212.

Rosa CLS, Soares AG, Freitas DFGC, Rocha MC, Ferreira JCS \& Godoy RLO (2011) Caracterização físico-química, nutricional e instrumental de quatro acessos de tomate italiano (Lycopersicum esculentum Mill) do tipo 'Heirloom' produzido sob manejo orgânico para elaboração de polpa concentrada. Alimentos e Nutrição, 22:649-656.

Tavares CA \& Rodriguez-Amaya DB (1994) Carotenoid composition of Brazilian tomatoes and tomato products. Lebensmittel-Wissenschaft und-Technologie, 27:219-244.

Vilas Boas EVB, Chitarra AB, Maluf WR \& Chitarra MIF (1999) Influência do alelo alcobaça em heterozigose sobre a vida-deprateleira e qualidade pós-colheita de tomates. Ciência e Agrotecnologia, 23:650-657. 